\title{
Editorial
}

\section{Continued Efforts for Transparency and Inclusion}

The latest ALA Annual Conference in DC saw the unveiling of the action-oriented research agenda Open and Equitable Scholarly Communications: Creating a More Inclusive Future, developed with leadership from the ACRL Research and Scholarly Environment Committee. It is a key milestone in the association and in the profession by encouraging the community to make the scholarly communications system more open, inclusive, and equitable by outlining trends, encouraging practical actions, and clearly identifying the most strategic research questions to pursue. The report punctuates conversations that the association has been having for the past few years and provides a framework for how to approach institutionalizing and modelling these values.

Over the past few years, College \& Research Libraries has worked within ACRL to be more inclusive and equitable by broadening the diversity of perspectives on the Editorial Board, inviting the expertise and experiences of its article peer reviewers, and making transparency and openness a priority of the journal. We also strive to be more inclusive and push the boundaries of research and to provide many perspectives and voices on topics that have not appeared in the journal previously.

The purpose of an academic journal is to promote dialogue and, as an editor, I am ever aware that this is an important responsibility that may entail addressing sensitive issues that prompt disagreement or controversy. Debate can stimulate understanding and it is always my hope that a variety of viewpoints are surfaced, resulting in a broader understanding and recognition of all viewpoints.

There has been a focus on representation in the reviewing boards of the ACRL publications, seeking to include multiple perspectives and experiences. I agree that the journal needs diverse representation on its Editorial Board and in its reviewers, which we have been working toward. Having diversity in our boards and reviewing pools demonstrates commitment to the value and exemplifies what we hope the profession will achieve.

College $\mathcal{E}$ Research Libraries has worked to expand the perspectives on the Editorial Board as well as with the (article) peer reviewer pool at large. I have discussed some of these efforts in previous editorials to be more transparent about how some of those decisions and invitations are made. Even so, we are always trying to improve.

\section{Efforts toward Transparency}

Transparency of process has also been addressed within several previous editorials. The primary example - "Opening the Black Box" - was intended to provide context to the process that an article submission goes through with targets and timelines. There has also been discussion of decision making, particularly about how individuals are selected for the editorial board or as article reviewers.

Recognizing the importance of transparency and open peer review, the journal has explored how to incorporate these values, with a pilot of a developmental review model (dis- 
cussed in a collaborative editorial "Considering Developmental Peer Review") and then the use of developmental review in the upcoming special issues for 2020 and 2021. Employing developmental review promotes transparency about guidance that is provided and learning that occurs in review and revision is, I believe, an ideal model. It shifts from a critical model to an educational and coaching model. Developmental review takes a lot of time, effort and commitment from all parties. However, the result is worth it. Manuscript quality improves, Authors grow and develop a deeper understanding of writing and the process of review. Ultimately, authors and reviewers involved build rapport and trust.

Despite these efforts, we can always do better. The recent response to the book review of Pushing the Margins: Women of Color and Intersectionality in LIS published in the July issue of $C \mathcal{E} R L$ demonstrates that we need to do better.

One of the questions raised was how we select reviewers for books. Matching books with book reviewers or paper submissions with article reviewers takes a fair bit of effort, especially with the breadth of scholarship in the profession. As I note above, the CERL Editorial Board and ACRL Publications Coordinating Committee have made ongoing efforts to better reflect our diverse membership on the boards. I have also made efforts to carry this initiative through to the group of reviewers in an attempt to increase the variety of expertise and experience. This may not seem difficult but sometimes, it can require a lot of effort-finding a willing reviewer who has demonstrated writing experience (i.e., is published), expertise in certain topics or areas of research, and time among their other commitments.

\section{The Reviewing Process for Articles}

To share greater insight into the journal processes, there are several roles that library scholars and practitioners have volunteered to take on. The Editorial Board is advisory to the editor and helps prioritize and develop initiatives that the journal may undertake. These individuals have also served, and usually continue to serve, as either article peer reviewers or book reviewers or both. I believe that it is important for editorial board members to have had the experience of being a reviewer or book reviewer for College $\mathcal{E}$ Research Libraries so that they have that context in order to provide guidance for the journal. The process for becoming a Board Member is the same process that ALA uses for other service opportunities - the volunteer form. The names of the volunteers (and it is usually about 50) are forwarded to the Editor. In reviewing the names to pass on to the Board and the Publications Coordinating Committee, there are two factors that weigh heavily: the record of previous service to the journal and the publication record of the individual in terms of experience with authoring research articles and area of research focus. Given that there is not a lot of turnover on the Board, there are usually only two or three names put forward every couple of years.

So what happens to the rest of those potential volunteers? In my review of the publication records and specializations of the individuals, I also identify potential article reviewers. Given that they have indicated an interest in getting involved with $C \mathcal{E} R L$, I reach out to many of them and invite them to serve as article reviewers for the journal. Many of them accept. In the past, it has occurred that some of these individuals have again indicated interest in the serving on the editorial board and, given their demonstrated commitment, have been selected.

The other way is that a need is identified, either by seeing a gap in research expertise or not having a reviewer available on a specific topic. Then, I do a literature search to identify someone who has published studies on the topic area and invite them. Infrequently, someone 
will contact me (outside of ALA's volunteer cycle) and volunteer. Provided, the individual has a publication record and a needed area of specialization, they are invited to be an article reviewer.

In expanding the pool of reviewers, my goal is to bring more diverse perspectives to the journal. There are some individuals who have published outside of librarianship and bring that perspective. There are some who have published in less formal and more practical venues. However, because we are asking them to assess submissions on original research in a research article format, it is necessary that the reviewer have demonstrated experience with publishing in the topic area as well as a recognized area of expertise in librarianship (although that ranges very broadly).

In assigning submissions for review, the editor does their best to identify a reviewer whose experience or expertise align with the topic of the paper. Further, the reviewer does their best to provide a timely, expert and objective review. Periodically, a reviewer may let the editor know that they may not have the best background for the topic. In most cases, the editor identifies another reviewer. Sometimes the journal may not have a current reviewer available with the appropriate expertise-in which case, the editor may identify someone with expertise and invite her or him to be a reviewer with that paper submission in mind. That said, there is some reluctance to do this as it causes a significant lag in getting the paper through the review process and a timely response and decision to the author.

\section{The Reviewing Process for Books}

To offer additional transparency around book reviews, I am going to provide some context to the process. For the most part, the book reviewers are a distinct group from the article reviewers however there are a very few exceptions where a person might do both. The purpose, processes, and the products are quite different between book reviews and articles. While the article review is meant to provide constructive feedback to the author and an assessment to the editor, the book reviewer authors a review for publication and consideration by those in the profession.

There is a recognized group of individuals who have committed to do book reviews for the journal. Those individuals are identified prior to being assigned a review and are generally selected, based on expertise and to a degree, practical professional experience. They are asked to review books that fall within their focus. The journal gets a wide variety of books to review, just as it gets a wide variety of papers submitted, and we try to match up the book or paper with a reviewer who has knowledge on the topic. Thus, different books call for different individuals.

Some titles may be more suitable to be reviewed by practicing librarians. Whereas other titles may be more appropriate for library faculty or those with research experience. Before placing a book for review, each potential reviewer is asked to look at the information about the book, typically what is provided via the publisher's website, so they can evaluate the title for their ability to speak to the content of the book. If they agree that they will be able to review it, they are sent a copy of the book. The editor tries to be deliberate about the placement process as to maximize a positive outcome. Periodically, a reviewer agrees to review a title but then returns the book because the reviewer did not believe they could do it justice for one reason or another. This does not occur often because the book reviewers make every effort to live up to their commitment and provide a timely review. 
When inviting a new reviewer, they are given a trial title to assess their abilities as a reviewer. This is particularly important if they have not written a review before. The book review editor spends some time speaking with them about what to consider and how to structure the review and refers them to several different published reviews from CERL. The book review editor also provides feedback on the draft if a book reviewer is struggling, offering ways to improve it. There have been reviews that have never been published because they were of poor quality.

However, there are times, as with the recent book review in CERL on Pushing the Margins, that prompt a very strong response. Some of the discussion of this review revolved around the value of providing some transparency into the book review process and, not inconsistent with the move into developmental review, to reveal some of the learning process of the book reviewer and how the collection informed their understanding of the topic. While it was not the intent, it is clear in retrospect, that the published review shifted the focus from the experience and voices of the authors in the collection to the reviewer experience. That is something that I regret.

I want to commend all of our book reviewers for their contributions to the journal. They are volunteers who take on this task as a service to the profession. At times, it does take courage and self-reflection to acknowledge ones challenges when completing a review, which at times may provide the most value to the reader who is weighing exploring the full content of a title.

\section{The Question of Quality and Rigor}

Some of the questions around how reviewers are selected and what the expertise looks like are consistent with some of the questions that I have had about quality and rigor in scholarship. These are somewhat traditional terms that pervade scholarly research. They are also somewhat vague - I have had scholars in their field say to me that "I know quality when I see it." The lack of transparency in that kind of statement bothers me. It is also not uncommon to have new librarians who are required to publish ask what the criteria or standards are"What does quality look like?"; "How do I know that a study or even the journal is rigorous enough?" These questions are not unreasonable, particularly if they are assessed annually for evaluations or during promotion and tenure on their research and publication.

My goal is to ensure that $C \mathcal{E} R L$ is more transparent and more inclusive. Peer review has long stood as a marker of "quality" - that other scholars and practitioners in the field with their own experience and specialization are the ones to assess (dare I say, judge?) the quality, originality and rigor of research. The ideal is an impartial review that looks at the merits of the research and its potential impact on the scholarship or practice and no other factors. However, I don't want this to be limiting or make the journal exclusive.

The report on Open and Equitable Scholarly Communications: Creating a More Inclusive Future also raised similar questions under Rethinking What Counts and urging "researchers to consider the ways in which value is assigned to scholarly materials, particularly as they relate to promotion, retention, and tenure decisions, and to consider the role librarians might play in influencing ongoing efforts to refine them." This is very true. Fundamentally, people do what they are rewarded for, whether it is positive annuals reviews, tenure, or advancement. At an institution that requires research and publication, if the awarding of tenure is based on restrictive criteria - for example, if a department or college requires publication in certain venues (it is not uncommon to have journal lists or rankings), that is what the majority of scholars will likely do. 
This adherence to scholarly journals and traditional research articles is a topic that I have been considering for a while. It was recalled by a brief comment in the report also caught my eye-"Why only scholarly?" (p. 3). It aligns with some of the thoughts I have had about the format of journal articles and what we can do to push that boundary. Fortunately, $C \& R L$ and $C \mathcal{E} R L$ News have a good balance where CERL takes the more "traditional" research articles and CERL News publishes best practices, case studies, practical innovations, and less formal pieces. However, with the opportunities of technology and media, along with the focus on community-building and dialogue, we should be able to do more.

\section{Formalizing these values}

It was pointed out to me that, as the editor, I have been focused on operations and have not reached out to our community, to those who are committed to evolving scholarly communication and having a more open and equitable environment. As cliché as it may sound, it does take a village. I am merely the steward of the journal, it is owned by and responsible to academic librarians, the association membership, the authors and readers, the reviewers and the editorial board.

As such, I agree that there should be more involvement and inclusion in the journal. The volunteers we currently have are committed and bring valued expertise - and they also recognize the need for more involvement and inclusion, not just because there are definitely gaps in our resources, and in many emerging and significant topics, but also in the perspectives that inform the future direction of the journal.

I invite individuals to contact me or a member of the Editorial Board if they are interested in serving as a book reviewer for the journal or as a reviewer for paper submissions or volunteering in another way for the journal.

With openness comes different perspectives and the need to be aware of the many voices in our community. What are the aspects or perspectives that have been missed? What perspectives can we include moving forward? Is there a way to provide multiple perspectives? The idea of openness in terms of inviting access and participation is appealing. CERL has taken advantage of some of the technology and functionality built into the online platform but many of the processes are what they were when the journal format was print. We have the technology and the motivation to include more voices and to promote dialogue in the journal.

Part of reshaping scholarly communication is looking at our own structure and operations with the journal. To that end, there are some efforts that we are planning:

Moving forward, we will be having additional conversations around equity, diversity and inclusion as well as how we can effectively formalize these values in the journal. To this end, the Editorial Board has been asked to form a taskforce, looking at how the journal as a whole can advocate for more open and equitable scholarly communication, not only in what it publishes but also in how it operates.

The Editor and Editorial Board will discuss book reviews and the process for them as well as how they might evolve, given advances in engagement through technology, the commitment to openness and a desire to provide more diverse and potentially multiple perspectives.

In addition, we will continue to delve into the process for article reviewing (aligning with developmental or open peer review), including the selection of reviewers.

We will be seeking a second review of the title, Pushing the Margins, to be published in a future issue. 
The Editor and the Editorial Board will be setting priorities for the journal as well as looking at ways to evolve to meet the needs of current and future scholars and practitioners in the profession.

As I have said (and firmly believe), the editor's job is to steward the journal and facilitate the publication process to ensure an open and equitable environment that invites multiple perspectives and raises dialogue to discourse, that is representative of what is happening in the profession and that seeks to maintain high standards of ethical and social responsibility. In order to achieve these goals, it does take the commitment of members to engage in dialogue, debate issues and provide varying perspectives. 